
JNM
J Neurogastroenterol Motil, Vol. 22 No. 2 April, 2016
pISSN: 2093-0879 elSSN: 2093-0887
http://dx.doi.org/10.5056/jnm15197
Journal of Neurogastroenterology and Motility

\title{
The New Calcium Imaging Trend (Front Cell Neurosci 2015;9:436)
}

Hyun Jin Kim

Department of Internal Medicine, Gyeongsang National University College of Medicine, Jinju, Korea

\section{Summary}

Calcium imaging is a technique for intracellular calcium measurement, and it is important to understand the neural and glial functions. Genetically encoded $\mathrm{Ca}^{2+}$ indicators have been used extensively in many body systems to detect $\mathrm{Ca}^{2+}$ transients associated with neuronal activity. The aim of this article is to utilize a number of cell-specific promoters that express the $\mathrm{Ca}^{2+}$ indicator GCaMP3 in different classes of neurons and glia to determine their effectiveness in measuring activity in enteric neural networks during colonic motor behaviors. ${ }^{1}$

The authors found that the activity in glial networks appeared to follow neural activity but continued long after neural activity had waned. With these new tools an unprecedented level of detail can be recorded from the enteric nervous system (ENS) with minimal manipulation of tissue. These techniques can be extended in order to better understand the roles of particular enteric neurons and glia during normal and disordered motility.

\section{Comments}

ENS is composed of neurons and glial cells. Enteric glial cells are located in close contact with enteric neurons within the ganglia, along inter-ganglionic connectives of the myenteric and submucosal plexus, and can also be found in the extra-ganglionic layers of the gut wall, ${ }^{2}$ glial cells shows dynamic responses to neuronal inputs and have the apparatus to sequester and release the neuro-active factors. Nonetheless, whether these cells indeed regulate synaptic transmission in a physiological context such as gut motility pattern is not well known.

The live imaging of neuron-glia interaction is very important in understanding these functions. The measuring of intracellular calcium can be done using fluorescent indicators and it has become the most popular technique. It consists of 2 steps, in the first step primary ENS cultures are loaded with the $\mathrm{Ca}^{2+}$ indicator dye, Fluo4-AM or Fura-2, and the second step is stimulated by $75 \mathrm{mM}$ $\mathrm{K}^{+}$depolarization. ${ }^{4}$

However, traditional $\mathrm{Ca}^{2+}$ imaging techniques have limitations. Calcium imaging bleaching changed indicators cannot cross the cell membrane, and the intracellular concentration might decrease during the experiment. This means that long-term recording is difficult, and the recording of drug response is also limitated.

The new calcium imaging uses GCaMP3 mice. There are several kind of mice: Wnt1-Cre, Rosa26-Lox-STOP-LoxGCaMP3 mice (GCaMP3 targeted to neural crest derivatives, including enteric neurons and glia via Wnt1-Cre transgenic mice; Jax \# 009107; heretofore referred to as Wnt1-GCaMP3); GFAPCre, Rosa26-Lox-STOP-Lox-GCaMP3 (GCaMP3 targeted to glia via mice expressing Cre from the human GFAP promoter; Jax \# 004600; heretofore referred to as GFAP-GCaMP3); ChAT-Cre, Rosa26-Lox-STOP-Lox-GCaMP3 (GCaMP3 targeted to cholinergic neurons via ChAT-Cre BAC transgenic mice; MMRRC \#37336; heretofore referred to as ChAT-GCaMP3); and nNOS-

Received: December 17, 2015 Revised: None Accepted: December 26, 2015

(c) This is an Open Access article distributed under the terms of the Creative Commons Attribution Non-Commercial License (http://creativecommons. org/licenses/by-nc/4.0) which permits unrestricted non-commercial use, distribution, and reproduction in any medium, provided the original work is properly cited.

*Correspondence: Hyun Jin Kim, MD Department of Internal Medicine, Gyeongsang National University College of Medicine, 72 Gangnam-ro, Jinju 52727, Korea Tel: +82-55-750-8833, Fax: +82-55-750-8822, E-mail: imdrkim@naver.com 
CreER, Rosa26-Lox-STOP-Lox-GCaMP3 (GCaMP3 targeted to nitrergic neurons via nNOS-CreER transgenic mice; Jax \#014541; heretofore referred toasnNOS-GCaMP3). Mice be expressing a conditional (ie, Cre-dependent) allele of GCaMP3 in the Rosa26 locus (Rosa26-Lox-STOP-Lox-GCaMP3). Also, by using ChAT-GCaMP3 and nNOS-GCaMP3 mice we can begin monitoring $\mathrm{Ca}^{2+}$ transient activity in broadly defined cholinergic and nitrergic neurons in myenteric and submucosal ganglia, without the necessity of time-consuming post-staining immunohistochemistry, as was previously necessary. ${ }^{6}$ In conclusion the new technique should be develop the emerging new calcium imaging technique.

\section{Financial support: None.}

\section{Conflicts of interest: None.}

\section{References}

1. Hennig GW, Gould TW, Koh SD, et al. Use of genetically encoded calcium indicators (GECIs) combined with advanced motion tracking techniques to examine the behavior of neurons and glia in the enteric nervous system of the intact murine colon. Front Cell Neurosci 2015;9:436.

2. Gershon MD, Rothman TP. Enteric glia. Glia 1991;4:195-204.

3. Perea G1, Navarrete M, Araque A. Tripartite synapses: astrocytes process and control synaptic information. Trends Neurosci 2009;32:421431.

4. Boesmans W, Martens MA, Weltens N, et al. Imaging neuron-glia interactions in the enteric nervous system. Front Cell Neurosci 2013;7:183.

5. Zariwala HA, Borghuis BG, Hoogland TM, et al. A Cre-dependent GCaMP3 reporter mouse for neuronal imaging in vivo. J Neurosci 2012;32:3131-3141.

6. Okamoto T, Bayguinov PO, Broadhead MJ, Smith TK. $\mathrm{Ca}^{2+}$ transients in submucous neurons during the colonic migrating motor complex in the isolated murine large intestine. Neurogastroenterol Motil 2012;8: 769-778. 